\title{
Prediction of iceberg trajectories for the North Atlantic and Arctic Oceans
}

\author{
Grant R. Bigg and Martin R. Wadley \\ School of Environmental Sciences, University of East Anglia, Norwich, United Kingdom \\ David P. Stevens and John A. Johnson \\ School of Mathematics, University of East Anglia, Norwich, United Kingdom
}

\begin{abstract}
Icebergs are a well-known hazard for shipping. Their study also provides information about diverse geophysical processes, as varied as ocean circulation, air-sea fluxes, calving rates of glaciers or the mass balance of ice sheets. As a first step to obtaining this information from iceberg data we have developed a model of iceberg drift driven by ocean and atmospheric forcing derived from general circulation models. We have applied the drift model to a distribution of typical icebergs released from the main tidewater glaciers of the North Atlantic and Arctic Oceans. We demonstrate that the main driving force of iceberg motion is rooted in the unsteady component of oceanic advection. From simulated trajectories we are able to reproduce the observed southwards limit of iceberg penetration and demonstrate sometimes surprising geographical links between iceberg origin and ultimate melting zones.
\end{abstract}

\section{Introduction}

Despite the hazard icebergs pose for shipping, and the intensive efforts of the International Ice Patrol to chart iceberg positions in the Labrador Sea since the Titanic disaster in 1912 [Strübing, 1974], relatively little is known about long-term iceberg trajectories and origins. Most synthesising research has focused on the Labrador Sea [Gustajtis and Buckley, 1978; Robe et al., 1980; Marko et al., 1982; Murphy and Anderson, 1985 and Venkatesh and El-Tahan, 1988]. There have been a few attempts to model iceberg drift over short distances [Smith and Banke, 1983; Isaacson and McTaggart, 1990; Smith, 1993], and one for a few hundred kilometres [Løset, 1993], but with relatively limited observational data to validate the models. No attempt has been made to reproduce the North Atlantic iceberg field and, as a consequence, to understand the dynamics dominating long-term iceberg drift on ocean basin scale.

In this paper we develop a model of iceberg trajectories. This will allow us to understand not just iceberg dynamics, but also to remotely explore the circulation of the relatively inaccessible polar oceans, both today and in the geological past, and also to predict glacial calving rates for the many unmonitored major tidewater glaciers of the polar seas.

\section{Model}

To model an iceberg's trajectory, from its glacial release to its ultimate melting, requires a model of both its dynamics and

Copyright 1996 by the $\Lambda$ merican Geophysical Union.

Paper number 96GL03369.

0094-8534/96/96GL-03369\$05.00 thermodynamics. L $\phi$ set [1993] modelled the detailed thermodynamics of an individual iceberg, but, because of the number of icebergs needed to simulate flow from all major Arctic glaciers, we have used simpler parameterisations of the melting process, based on, but supplementing, those discussed by Weeks and Campbell [1973] and El Tahan et al. [1987]. These melting processes basically consist of basal melting due to forced convection, sub-surface keel melting due to buoyant convection and wave friction, and free-board and surface melting due to latent, sensible and solar heat fluxes. While the details of the melting parameterisation noticeably influence the trajectories, the main determinant is dynamical, and so a detailed description of the melting parameterisation and its effects are left to a more specialised paper on the iceberg trajectory model.

The basic dynamical equation describing iceberg motion has been fully described by Smith [1993], and is similar to that used by Smith and Banke [1983] and Løset [1993]. Our basic equation describing the horizontal motion of an iceberg of mass $M$ at position $X$, moving with horizontal velocity $V_{i}$, has one addition to Smith's - sea-ice drag - and is

$$
M \frac{d V_{t}}{d t}=-M f \times V_{t}+F_{a}+F_{w}+F_{r}+F_{s}+F_{p}
$$

where $f$ is the Coriolis force, $F_{a}$ is the wind drag, $F_{w}$ is the water $\mathrm{drag}, F_{r}$ is the wave radiation force, $F_{s}$ is the sea-ice drag (where applicable) and $\boldsymbol{F}_{\rho}$ is the horizontal pressure gradient force exerted on the water volume that the iceberg displaces. As in Smith [1993], the general drag relationship is given by

$$
F_{x}=\frac{1}{2} \rho_{x} C_{x} A_{x}\left|V_{x}-V_{t}\right|\left(V_{x}-V_{i}\right)
$$

where the subscript $x$ refers to air $(a)$, water $(w)$ or sea-ice $(s)$ respectively, $\rho_{x}$ is the appropriate density, $C_{x}$ is the form drag coefficient $\left(C_{a}=1.3, C_{w}=0.9,[\right.$ Smith, 1993] and, because of the similar media, $C_{s}=C_{w}$ ), and $A_{x}$ is the cross-sectional area of the portion of the berg being affected by the stressing medium in a vertical plane normal to the stressing flow, which has velocity $V_{x}$. Note that the form drag coefficients for an individual iceberg will depend on its shape [Smith, 1993]. We have chosen mean estimates here, because of the smoothness of the forcing fields, and as our aim is to reproduce the general North Atlantic iceberg distribution, rather than exact trajectories of particular bergs. The addition to Smith's [1993] model, $F_{s}$, is generally the smallest force term and could, in most, but not all, circumstances be neglected with little error. The wave radiation force, as in Smith [1993], is

$$
F_{r}=\frac{1}{4} \rho_{n} g a^{2} L \frac{V_{a}}{\left|V_{a}\right|}
$$


where $L$ is the length of the berg normal to incident waves of amplitude $a$ which are assumed to have the same direction as $V_{a}$. Each berg is assumed to be rectangular, with a length to width ratio of 1.5:1.0 (similar to observations in Dowdeswell et al. [1992]) and is assumed to be oriented so that $V_{a}$ is $45^{\circ}$ to the left of the berg (in the Northern Hemisphere). Icebergs tend to preferentially erode laterally rather than vertically so a berg is allowed to roll over instantaneously when the Weeks-Mellor criterion of stability is exceeded [Weeks and Mellor, 1978].

The pressure gradient force, $F_{p}=-M(\nabla P) / \rho_{w}$, is of fundamental importance, as it is the basic force causing motion in the oceanic environment of the iceberg, and is likely to be a major driver of the iceberg itself. This force can be found from the equation of motion for $V_{w}$, which is:

$$
\frac{d V_{w}}{d t}+f \times V_{w}=-\frac{1}{\rho_{w}} \nabla P-\frac{1}{\rho_{w}} \frac{\partial \tau}{\partial z}
$$

where $P$ is the horizontal pressure field, $\tau$ is the wind stress and $z$ is the vertical coordinate. It is common [e.g. Smith and Banke, 1983; Loset, 1993] to assume that the ocean is in steady, geostrophic equilibrium and that the pressure force is then just $M f \times V_{w}$. Given that the iceberg is in the upper ocean it can be argued that the second term on the right hand side of Eq. (4), describing the transfer of momentum between the air and upper ocean, should also be considered. We will show, however, that the dominant term over much of the North Atlantic in a rearrangement of Eq. (4) for $F / M$ is the material derivative $\mathrm{d} V_{w} / \mathrm{d} t$ (including non-linear advection terms), and that this component of $F_{p}$ is the principal factor needed to be able to reproduce realistic iceberg distributions. The importance of this term lies not only in the strong seasonal variability in both atmospheric and oceanic flows in the polar seas, but also in the non-linearities induced by the strongly horizontally sheared flows in the Labrador and Greenland Seas.

In the model an individual iceberg is thus forced by a simple discretisation of Eq. (1) [Smith, 1993], using timesteps of the order of 2 minutes. The atmospheric parameters required by the iceberg model were supplied from the climatology of an atmospheric general circulation model (GCM) [Valdes and Hall, 1994]. The necessary oceanic parameters were obtained from a robust diagnostic (as in, for example, the FRAM Group [1991]) simulation of the circulation of the North Atlantic and Arctic Oceans at $1^{0}$ horizontal resolution, driven by Valdes and Hall's [1994] winds. Monthly average data were available from each model, and were linearly interpolated to the iceberg model timestep. Monthly sea-ice fields were digitised from a climatology of Arctic sea-ice thicknesses [Bourke and Garrett, 1987]. The effect of wind forcing of higher frequency than monthly averages is significant but not dominant. This is also true of the influence of oceanic eddies. Both of these effects change the details of the trajectories but not their general pattern. Also note that while Smith [1993] allowed $V_{w}$ to vary with depth the similarity of the ocean forcing in the top two layers meant that we did not allow for $\mathrm{d} V_{w} / \mathrm{d} z$ in $F_{w}$, and will therefore somewhat over-estimate the water drag.

\section{Iceberg seeding}

To simulate the iceberg limit and density over the Vorth Atlantic and Arctic it was necessary to seed the model with bergs off-shore of all major source glaciers (a total of 36 sites. see Figure 2). Each glacier will produce a distribution of sizes and shapes of bergs, but several studies suggest that the number of bergs follows a lognormal function of length, with a sharp decline in numbers above $1 \mathrm{~km}$ but relatively large numbers of bergs under 500m in length [Weeks and Mellor, 1978; Morgan and Budd, 1978; Dowdeswell et al., 1992]. We therefore modelled up to ten different initial sizes of bergs from each major source point, with all sites having at least the smallest five size classes but only a few having all ten. The ten initial widths ranged from $67 \mathrm{~m}$ to $1 \mathrm{~km}$, with draughts set to $300 \mathrm{~m}$, or the berg width, whichever was smaller. Rough estimates of individual glacier calving rates were

\section{a}

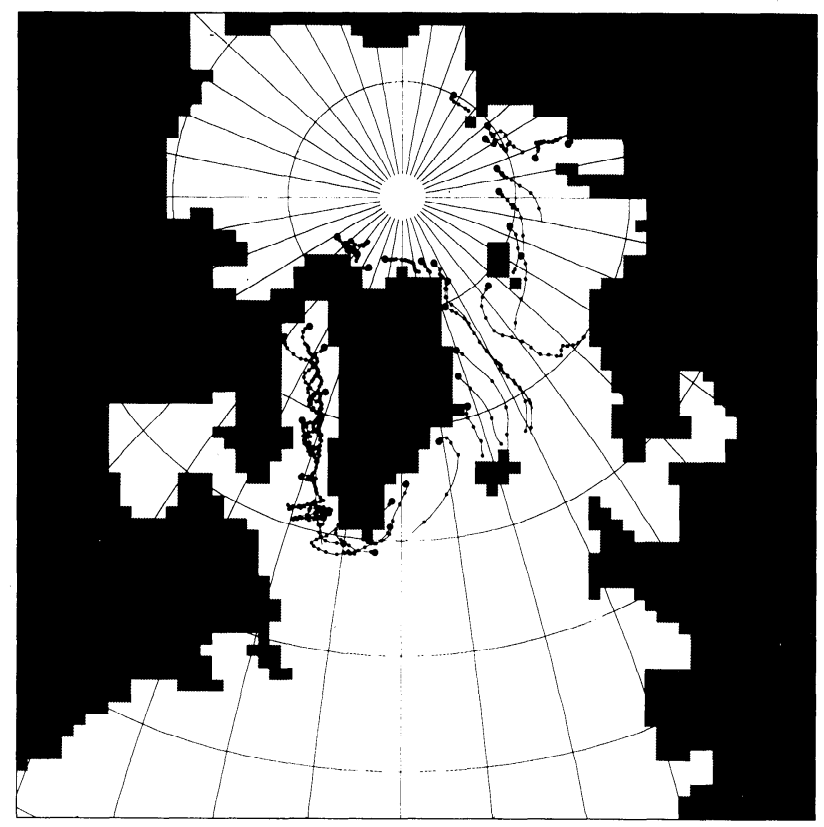

b

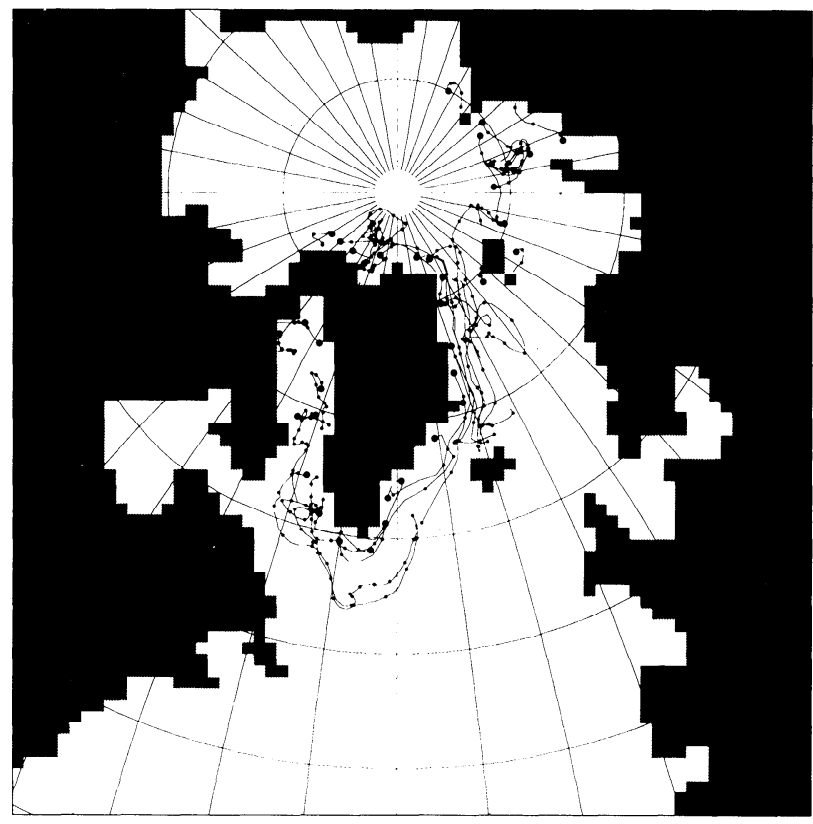

Figure 1. Effect of adding $\mathrm{d} V_{w} / \mathrm{d} t$ to the equation of iceberg motion. (a) shows a 1 July release of size class 5 icebergs without this term, while (b) uses exactly the same initial conditions but includes $\mathrm{d} V_{w} / \mathrm{d} t$. The large dots denote the release sites and every 20 days each trajectory is marked by a small dot. 
derived from topographic and bathymetric charts using the formula of Pelto and Warren [1991] and these were used to decide on the number of classes seeded for each source.

Icebergs were released from each starting location at four times in a year. They were followed until they either collided with land or melted below $0.25 \%$ of the mass of the smallest size class. If bergs entered water which was too shallow for their draught they were grounded and allowed to melt until small enough to continue.

\section{Results}

Previous iceberg models [Smith and Banke, 1983; Lфset, 1993] have assumed that the pressure force driving icebergs was in geostrophic equilibrium. Smith [1993] added the material derivative, $\mathrm{d} V_{w} / \mathrm{d} t$, to his pressure force but, in the very short simulations that he undertook, the iceberg motion was dominated by inertial oscillations and consequently he makes no comment on the need for this term. In Figure 1 we show the trajectories for all bergs initially $500 \mathrm{~m}$ in length for a July release both with (Figure 1b) and without (Figure 1a) the material derivative term included in $\boldsymbol{F}_{p}$. The difference is startling. Without $\mathrm{d} \boldsymbol{V}_{w} / \mathrm{d} t$ icebergs from Greenland and the Canadian Arctic are unable to enter the Labrador Current, or remain in it if they start near the Labrador coast. The major risk zone to shipping off the Grand Banks is thus not predicted. Similarly, in the Greenland Sea the bergs originating from East Greenland tend not to remain in the East Greenland Current but move southeastwards into the NE Atlantic, where very few, if any, icebergs have been recorded [Couper, 1983]. The oceanic flow in both regions is not purely geostrophic, both because of the strongly modulated seasonal cycle in atmospheric forcing and, more importantly, because of high horizontal shear in the strong boundary currents, which results in the non-linear terms in the equation of motion playing a significant role in long-term iceberg motion (Eq. (4)).

Combining all simulations, of all classes and seasonal releases, the observed iceberg limits are reasonably well simulated (Figure 2). Note, however, that the distributions from distinct size classes and seasonal releases form distinct subsets of the whole. These limits tend to correspond to winter/spring conditions in the model, while the minimum iceberg extent is in the autumn. In this latter season icebergs are mostly found only within $1000 \mathrm{~km}$ of their source glacier. There is a rapid expansion in extent in the winter season, to the limits shown in Fig. 2 by mid-winter. This period of maximum extent remains into the spring and only begins to retreat, less slowly than the winter expansion, in the summer.

Figure 2 shows that the southern limit in the Labrador Current is not quite as far south as observed. This is probably due to the modelled ocean currents in this area not penetrating as far south as in reality - a general problem with ocean models in this area [Wadley et al., 1996]. It is noteworthy that both the calving time and the size of the bergs has a significant effect on the final trajectory - no one season or size alone defines the limits. A few bergs travel distinctly further east than expected, probably because of the inaccuracy of the melting parameterisation at higher temperatures, but the observed limits are approximate and real rogue bergs have been recorded as far south and east as the Azores or the Shetlands respectively [Couper, 1983]. The few poor trajectories may, however, have implications for the actual calving of bergs from particular glaciers. This will be pursued in a later paper.

\section{Conclusions}

Icebergs are subject to a number of forces, all of which may be important in particular circumstances, but the dominant driving

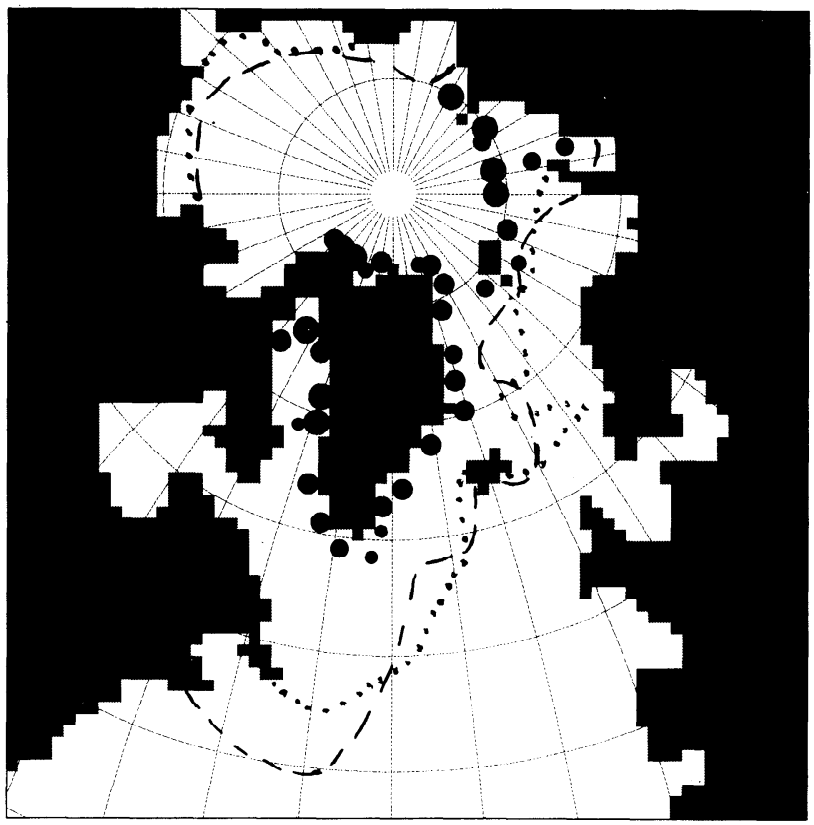

Figure 2. Chart of modelled (dotted line) and observed (dashed line) iceberg limits. The observed iceberg limit is a reconstruction from several sources [Couper, 1983; Sater et al., 1971; Herman et al., 1989] and can only be approximate. Release sites of icebergs are also shown by circles. The diameter of the circles is proportional to the number of size classes of bergs released from each site, with the smallest circle denoting releases of bergs no larger than $500 \mathrm{~m}$ in length (size classes 1-5) and the largest releases of bergs up to $1 \mathrm{~km}$ in length (all 10 size classes).

force, without which long-term, realistic iceberg trajectories are not obtainable, is non-linear advection in the ocean current, $\mathrm{d} \boldsymbol{V}_{w} / \mathrm{d} t$. Icebergs have been monitored for their hazard to shipping but rarely are individual bergs followed over many months and hundreds of kilometres. The present work will help to determine the source of icebergs that pose hazards. For instance, Gustajtis and Buckley [1978] suggested the Labrador bergs originated from southern Greenland and flowed across Davis Strait, bypassing Baffin Bay. In contrast Marko et al. [1982] thought western Greenland bergs travelled clockwise about Baffin Bay before moving south. Our model, however, suggests that most southern Greenland bergs do indeed stay out of Baffin Bay and cross the very southern end of Davis Strait, while western Greenland bergs tend to travel southwards, with only those from the northwest of Greenland showing anticlockwise rotation.

We have also shown the importance of the time of year and size distribution of iceberg production and, by implication, that iceberg distribution may be useful in determining glacier calving rates, and hence the mass balance of the Greenland Ice Sheet.

Acknowledgements. The authors thank Paul Valdes for supplying the atmospheric model results used in this study. This work was supported by grant number GST/02/1179 of the Natural Environmental Research Council of the United Kingdom.

\section{References}

Bourke, R. H., and R. P. Garrett, Sea-ice thicknesses in the Arctic Ocean, Cold Reg. Sci. Technol., 13, 259-280, 1987.

Couper, A. D. (editor) The Times Atlas of the Oceans, 272pp., Times Books, London, 1983.

Dowdeswell, J. A., R. J. Whittington, and R. Hodgkins, The sizes, frequencies, and freeboards of East Greenland icebergs observed using ship radar and sextant, J. Geophys. Res., 97, 3515-3528, 1992. 
El Tahan, M. S., S. Venkatesh, and H. El Tahan, Validation and quantificative assessment of the deterioration mechanisms of Arctic icebergs, J. Offshore Mech. Arctic Eng., 109, 102-108, 1987.

FRAM Group, An eddy-resolving model of the Southern Ocean, Trans. Am. Geophys. Un., 72, 169, 174-175, 1991.

Gustajtis, K. A., and T. J. Buckley, A seasonal iceberg density distribution along the Labrador coast, in Fourth Int. Conf. on Port and Ocean Engineering under Arctic Conditions, edited by D. B. Muggeridge, pp. 972-983, Memorial University of Newfoundland, 1978.

Herman. Y., J. K. Osmond, and B. L. K. Somayajulu, Late Neogene Arctic paleoceanography: micropaleontology, stable isotopes and chronology, in The Arctic Seas, edited by Y. Herman, pp. 581-655, Van Nostrand Reinhold, New York, 1989.

Isaacson, M., and K. A. McTaggarh, Modelling of iceberg drift motions near a large offshore structure, Cold Reg. Sci. Technol., 19, 47-58, 1990.

Løset, S., Thermal energy conservation in icebergs and tracking by temperature, J. Geophys. Res., 98, 10,001-10,012, 1993.

Marko, J. R., J. R. Birch, and M. A. Wilson, A study of long-term satellite-tracked iceberg drifts in Baffin Bay and Davis Strait, Arctic, 35, 234-240, 1982.

Morgan, V. I., and W. F. Budd, The distribution, movement and melt rates of Antarctic icebergs, in Proceedings of the First Conference on Iceberg Utilization for Freshwater Production, edited by A. A. Husseiny, pp. 220-228, Iowa State University, 1978.

Murphy, D. L., and I. Anderson, Evaluation of the International Ice Patrol drift model, Rep. Int. Ice Patrol, 1985 Season, USCG, 1985.

Pelto, M. S., and C. R. Warren, Relationship between tidewater glacier calving velocity and water depth at the calving front, Ann. Glaciol.. 15, 115-118, 1991.

Robe, R. Q., D. C. Maier, and W. E. Russell, Longterm drift of icebergs in Baffin Bay and the Labrador Sea, Cold Reg. Sci. Technol., 1, 183193, 1980.

Sater, J. E., A. G. Ronhovde, and L. C. Van Allen, Arctic environment and resources, 309pp., Arctic Institute of North America, Washington, 1971.

Smith, S. D., and E. G. Banke, The influence of winds, currents and towing force on the drift of icebergs, Cold Reg. Sci. Technol., 6, 241245, 1983.

Smith, S. D., Hindcasting iceberg drift using current profiles and winds, Cold Reg. Sci. Technol., 22, 33-45, 1993.

Strübing, K., Eisberge im Nordatlantik - 60 Jahre International Ice Patrol, Der Wetterlotse, 26, 141-160, 1974.

Valdes, P. J., and N. M. J. Hall, Mid-latitude depressions during the last ice age, in Long term climate variations - Data and modelling, edited by J. C. Duplessey, pp. 511-531, Springer-Verlag, Berlin, 1994.

Venkatesh, S., and M. El. Tahan, Iceberg life expectancies in the Grand Banks and Labrador Sea, Cold Reg. Sci. Technol., 15, 1-11, 1988.

Wadley, M. R., G. R. Bigg, D. P. Stevens, and J. A. Johnson, Sensitivity of the North Atlantic circulation to surface forcing in an ocean general circulation model, J. Phys. Oceanogr., 26, 1129-1141, 1996.

Weeks, W. F., and W. J. Campbell, Icebergs as a fresh-water source: an appraisal, J. Glaciol., 12, 207-233, 1973.

Weeks, W. F., and M. Mellor, Some elements of iceberg technology, in Proceedings of the First Conference on Iceberg Utilization for Freshwater Production, edited by A. A. Husseiny, pp. 45-98, Iowa State University, 1978.

G. R. Bigg, and M. R. Wadley, School of Environmental Sciences, University of East Anglia, Norwich NR4 7TJ, United Kingdom. (e-mail: g.bigg@uea.ac.uk; m.wadley@uea.ac.uk)

J. A. Johnson, and D. P. Stevens, School of Mathematics, University of East Anglia, Norwich NR4 7TJ, United Kingdom. (e-mail: d.stevens@uea.ac.uk; j.johnson@uea.ac.uk)

(Received July 30, 1996; revised October 21, 1996; accepted October 24, 1996.) 